\title{
Incorporating economies of scale
} in the cost estimation in economic evaluation of PCV and HPV vaccination programmes in the Philippines: a game changer?

Thanthima Suwanthawornkul ${ }^{1}$, Naiyana Praditsitthikorn ${ }^{1 *} \mathbb{0}$, Wantanee Kulpeng ${ }^{1}$, Manuel Alexander Haasis ${ }^{2}$, Anna Melissa Guerrero ${ }^{2}$ and Yot Teerawattananon ${ }^{1}$

\begin{abstract}
Background: Many economic evaluations ignore economies of scale in their cost estimation, which means that cost parameters are assumed to have a linear relationship with the level of production. Economies of scale is the situation when the average total cost of producing a product decreases with increasing volume caused by reducing the variable costs due to more efficient operation. This study investigates the significance of applying the economies of scale concept: the saving in costs gained by an increased level of production in economic evaluation of pneumococcal conjugate vaccines (PCV) and human papillomavirus (HPV) vaccinations.

Methods: The fixed and variable costs of providing partial (20\% coverage) and universal (100\% coverage) vaccination programs in the Philippines were estimated using various methods, including costs of conducting questionnaire survey, focus-group discussion, and analysis of secondary data. Costing parameters were utilised as inputs for the two economic evaluation models for PCV and HPV. Incremental cost-effectiveness ratios (ICERs) and 5-year budget impacts with and without applying economies of scale to the costing parameters for partial and universal coverage were compared in order to determine the effect of these different costing approaches.

Results: The program costs of the partial coverage for the two immunisation programs were not very different when applying and not applying the economies of scale concept. Nevertheless, the program costs for universal coverage were 0.26 and 0.32 times lower when applying economies of scale compared to not applying economies of scale for the pneumococcal and human papillomavirus vaccinations, respectively. ICERs varied by up to $98 \%$ for pneumococcal vaccinations, whereas the change in ICERs in the human papillomavirus vaccination depended on both the costs of cervical cancer screening and the vaccination program. This results in a significant difference in the 5-year budget impact, accounting for 30 and $40 \%$ of reduction in the 5 -year budget impact for the pneumococcal and human papillomavirus vaccination programs.

Conclusions: This study demonstrated the feasibility and importance of applying economies of scale in the cost estimation in economic evaluation, which would lead to different conclusions in terms of value for money regarding the interventions, particularly with population-wide interventions such as vaccination programs. The economies of scale approach to costing is recommended for the creation of methodological guidelines for conducting economic evaluations.
\end{abstract}

\footnotetext{
*Correspondence: naiyana.p@hitap.net; naiyana.pr@gmail.com

${ }^{1}$ Health Intervention and Technology Assessment Program, Ministry

of Public Health, Nonthaburi 11000, Thailand

Full list of author information is available at the end of the article
} 
Keywords: Cost estimation, Economic evaluation, Economies of scale, Human papillomavirus, Pneumococcal conjugate vaccine

\section{Background}

Health expenditure has risen for many years worldwide parallel with the demand for health care services [1]. As a result, when making decisions on the use of limited health resources, policy makers need to consider not only the clinical benefits but also economic information, including value for money and the budget impact of particular health interventions and technologies [2]. Even though cost is an important parameter for economic analysis, researchers often pay little attention to identifying accurate and reliable cost information compared to clinical parameters [3]. In common with the production and delivery of technologies in many industries, the unit cost of health technologies and interventions is likely to be affected by scale due to the efficiency gained by an increased level of production. This results in a non-linear function of the cost of production of health services or health technologies in relation to the size of production. Despite this, a few economic evaluation studies have incorporated economies of scale in their analysis [4]. The WHO's Choosing Interventions that are Cost-Effective (CHOICE) project recommends the application of economies and diseconomies of scale when estimating the costs and impacts of various interventions with different coverage levels $[5,6]$.

Further, the Reference Case developed by the International Decision Support Initiative (iDSI) underlines the need to apply economies of scale in cost estimation, where appropriate [7]. Although incorporating economies of scale in an analysis is very reasonable, it is methodologically challenging, especially in low- and middle-income countries where health information infrastructures have not been well established. Thus, this study aims to investigate the feasibility and significance of applying the economies of scale concept to the economic evaluation and budget impact analysis of economic models for pneumococcal conjugate vaccines (PCV) and human papillomavirus (HPV) vaccine in the Philippines. The vaccine cases were selected for this study because of two reasons. First, it has been well recognised that the cost of the supply chain and vaccine procurement can be significantly affected by the number of vaccinations [8]. Second, the Government of the Philippines set their milestone to increase budget allocation every year for expansion the newly introduced vaccines. Their main priorities are infants, children, women, and elderly persons nationwide [9]. Strengthening the evidence on financial sustainability through the finding from this study can support decision making in the expanded program on immunization.

\section{Methods \\ Model structures}

Two economic evaluation models used for previous economic evaluations of PCV and HPV in the Philippines were deployed in this study. Details of the models are described elsewhere in open-access journals [10, 11]. Briefly, the two models compared both the costs and outcome of the PCV and HPV vaccination with $0-1$ years for both boys and girls, and 11 years and above for girls, respectively. The models compared the vaccination programmes with the current practices, i.e. do nothing in the case of PCV and cervical cancer screening (visual inspection with acetic acid-VIA) in the case of HPV. The lifetime time horizons with the discount rate of $3.5 \%$ for both costs and outcome in terms of quality-adjusted life years (QALYs) were used consistently across the two models. Because this study focuses on applying the economies of scale concept to costing estimations, the epidemiological intervention effectiveness and utility information have been unchanged.

\section{Fixed costs}

Using the provider's perspective, the costs of the vaccination programmes were divided into two groups, i.e. fixed costs and variable costs. The fixed costs included cold chain-related infrastructure investment, which means that the costs of a functioning cold chain system were independent from the target population proportion to be covered by the vaccine programme. In other words, the higher the number of vaccinations provided was, the lower was the cold chain vaccination cost attached to each vaccine provided. The data on the cold chain investment in the Philippines were gathered from the Department of Health-Family Health Office, Ministry of Health (personal communication from programme manager of the Expanded Program on Immunization, the Philippines). Since the cold chain is used to support three different vaccination programmes, namely $\mathrm{PCV}$, $\mathrm{HPV}$, and inactivated polio vaccine, this joint cost was divided according to the number of vaccine dosages currently under the cold chain system. The PCV programme accounts for $55 \%$ of the total investment and the HPV programme accounts for $25 \%$. The costs are presented in Table 1. 
Table 1 Estimating cold chain investment cost per annum in relation to each vaccination programme

\begin{tabular}{lccc}
\hline Type of vaccine & No. of doses & Proportion & Investment in cold chain (USD per year) \\
\hline Pneumococcal conjugate vaccine & $6,600,000$ & 0.557 & 790,000 \\
Human papillomavirus vaccine & $3,044,100$ & 0.257 & 364,000 \\
Inactivated polio vaccine & $2,200,000$ & 0.186 & 263,000 \\
Total & $11,844,100$ & 1.00 & $1,417,000$ \\
\hline
\end{tabular}

\section{Variable costs}

The variable costs included vaccine acquisition costs, wastage costs, and logistic and administration costs. Originally, it was planned that the vaccine acquisition costs would be derived from a price survey among the vaccine companies. Despite requests directly from the Pharmaceutical Division of the Department of Health Philippines to vaccine companies, information about vaccine costs and administrative costs was not forthcoming. As such, the researchers used the current procurement prices for the scenario regarding the current vaccine coverage, i.e. 90,88 and $86 \%$ for the first, second, and booster dose of $\mathrm{PCV}$, respectively, the correspondence based on the 2013 coverage rates for the DPT-HepB-Hib vaccination for the first two doses and for the measles vaccination administered at the same time as the booster dose [9], and $10 \%$ for the HPV vaccination programmes were assumed to correspond to the achieved 2012 incorporate rate of pharmacy administration services regarding the drug price reference index of the $\mathrm{DOH}$ [12]. The researchers assumed the cheapest price for vaccine acquisition for $100 \%$ coverage of the HPV vaccine using the current GAVI's procurement prices (USD 10.30 for PCV10, USD 10.40 for PCV13, and USD 4.50 for HPV) $[13,14]$ and varied the prices between the current coverage and $100 \%$ coverage using a linear assumption. The vaccine wastage costs, and logistic and administration costs, were assumed to be at $25 \%$ of the vaccine acquisition costs according to the observed rates in Thailand [15]. These cost parameters are showed in Tables 2 and 3.

\section{Incorporating economies of scale}

For the cervical cancer modelling, the economies of scale were also applied to VIA screening and cryotherapy for the early stage of cervical cancer detected by the screening programme. The fixed costs included training and medical devices, e.g. cryotherapy units. The variable costs included labour costs and consumable materials such as acetic acid, $\mathrm{CO}_{2}$, etc. The data were collected from the $\mathrm{MOH}$ and are shown in Table 4.

The treatment costs for pneumococcal infection, including its complications and cervical cancer for human papillomavirus infection, were collected in the Philippines and in Thailand when the data in the
Philippines were not available. The details of these costs were available in previous publications $[10,11]$. Because the treatment costs depend on general access to the health facilities for each individual, the researchers did not apply economies of scale in the costing estimation for the treatments.

\section{Results}

The results are presented in terms of an incremental cost-effectiveness ratio (ICER) for each vaccination programme with different coverage scenarios. Because there are many options for cervical cancer prevention and control, two comparators were represented in the analysis: (1) HPV vaccination plus cervical cancer screening compared with cervical cancer screening alone; and (2) HPV vaccination alone compared with cervical cancer screening alone. The first comparator is in line with the current policy option in the Philippines, whereas the second comparison was made to highlight the impact of economies of scale approach to economic evaluation when both policy choices were applicable for the approach. The economic analysis applied the ceiling threshold of Php 120,000 (USD 2835) in line with previous policy decisions for determining the value of health investment in the Philippines context. If the ICER was below the ceiling threshold, the intervention was considered to be cost-effective. If the ICER was lower than zero in this study, the intervention was considered to be a cost-saving option. In addition, the government budget implications for each policy option during the next 5 years are presented. All costs are presented in US dollars, USD, for the year $2012($ Php $0.024=$ USD 1).

Table 5 shows a significant difference in the ICERs of PCV compared to the programme with no vaccination. Applying an economies of scale approach to estimating the cost of the vaccination programme accounted for a 62 and $71 \%$ reduction in ICERs for low vaccination coverage and up to 97 and $98 \%$ for high vaccination coverage in PCV10 and PCV13, respectively. It is noteworthy that the ICERs declined sharply with vaccination coverage equal to or above $80 \%$ as a result of herd protection. Nevertheless, the ICERs with an economies of scale approach did not change that policy conclusion-that PCV represents good value for money in the Philippine context. 


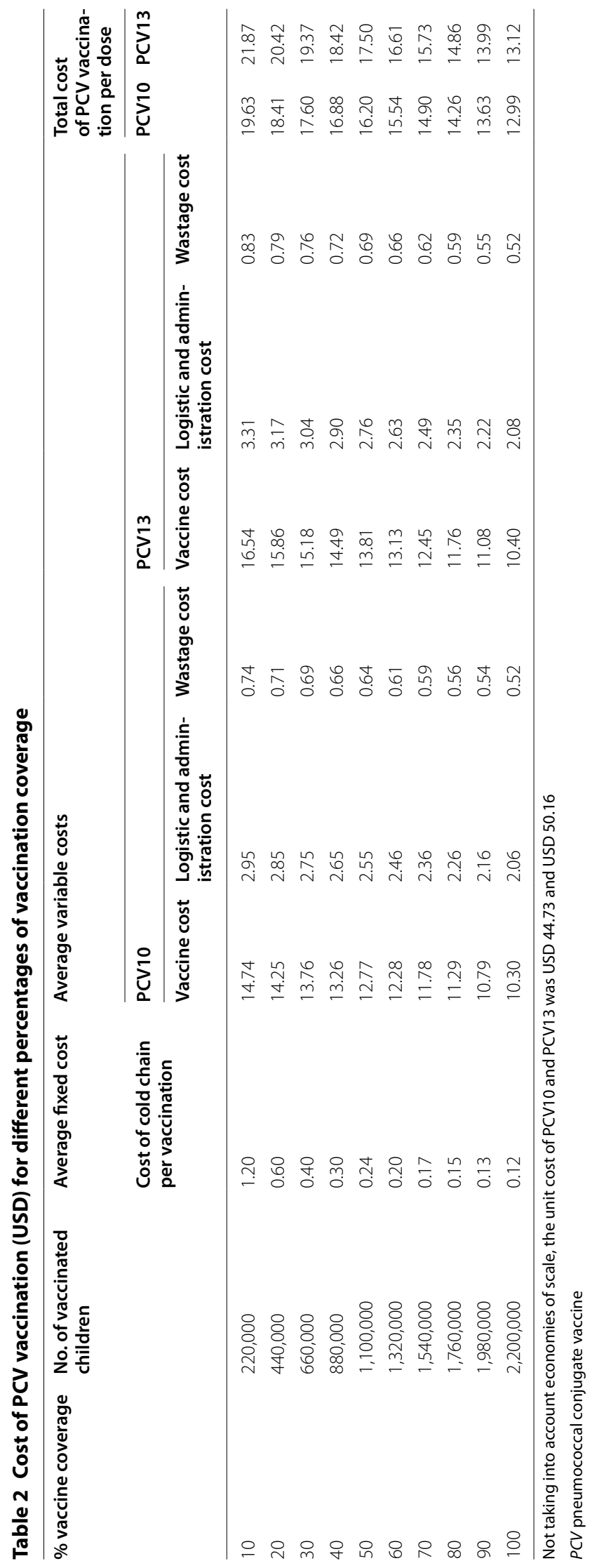


Table 3 Cost of HPV vaccination (USD) for different percentages of vaccination coverage

\begin{tabular}{|c|c|c|c|c|c|c|}
\hline \multirow[t]{2}{*}{$\%$ vaccine coverage } & \multirow{2}{*}{$\begin{array}{l}\text { No. of vaccinated } \\
\text { girls }\end{array}$} & \multirow{2}{*}{$\begin{array}{l}\text { Average fixed cost } \\
\text { Cost of cold chain } \\
\text { per vaccination }\end{array}$} & \multicolumn{3}{|c|}{ Average variable costs } & \multirow{2}{*}{$\begin{array}{l}\text { Total cost of HPV } \\
\text { vaccination per dose }\end{array}$} \\
\hline & & & Vaccine cost & $\begin{array}{l}\text { Logistic and admin- } \\
\text { istration cost }\end{array}$ & Wastage cost & \\
\hline 10 & 101,470 & 1.2 & 15.1 & 3.0 & 0.8 & 20 \\
\hline 20 & 202,940 & 0.6 & 13.9 & 2.8 & 0.7 & 18 \\
\hline 30 & 304,410 & 0.4 & 12.8 & 2.6 & 0.6 & 16 \\
\hline 40 & 405,880 & 0.3 & 11.6 & 2.3 & 0.6 & 15 \\
\hline 50 & 507,350 & 0.2 & 10.4 & 2.1 & 0.5 & 13 \\
\hline 60 & 608,820 & 0.2 & 9.2 & 1.8 & 0.5 & 12 \\
\hline 70 & 710,290 & 0.2 & 8.0 & 1.6 & 0.4 & 10 \\
\hline 80 & 811,760 & 0.1 & 6.9 & 1.4 & 0.3 & 9 \\
\hline 90 & 913,230 & 0.1 & 5.7 & 1.1 & 0.3 & 7 \\
\hline 100 & $1,014,700$ & 0.1 & 4.5 & 0.9 & 0.2 & 6 \\
\hline
\end{tabular}

Not taking into account economies of scale, the unit cost per dose of HPV was USD 20

HPV human papillomavirus vaccine

Table 4 Cost of cervical cancer screening (USD)

\begin{tabular}{|c|c|c|c|c|}
\hline$\%$ screening coverage & $\begin{array}{l}\text { No. of eligible women } \\
\text { per year }\end{array}$ & Unit cost of VIA screening & Unit cost of cryotherapy & $\begin{array}{l}\text { Total cost of cervical cancer } \\
\text { screening per woman }\end{array}$ \\
\hline 10 & 139,941 & 24 & 9 & 33 \\
\hline 20 & 279,882 & 12 & 5 & 18 \\
\hline 30 & 419,824 & 16 & 6 & 23 \\
\hline 40 & 559,765 & 12 & 5 & 18 \\
\hline 50 & 699,706 & 10 & 5 & 14 \\
\hline 60 & 839,647 & 12 & 5 & 18 \\
\hline 70 & 979,588 & 10 & 5 & 15 \\
\hline 80 & $1,119,530$ & 12 & 5 & 18 \\
\hline 90 & $1,259,471$ & 11 & 5 & 16 \\
\hline 100 & $1,399,412$ & 10 & 5 & 14 \\
\hline
\end{tabular}

Not taking into account economies of scale, the unit cost of cervical cancer screening was USD 35.44

VIA visual inspection with acetic acid

Figure 1 illustrates the budget implications of the PCV vaccination programmes, and the treatment of pneumococcal-related infections using and not using the economies of scale approach. The figure indicates that the 5 -year budget impacts of the vaccination programmes using the economies of scale approach accounted for only 30 and $40 \%$ of the budget estimation without using the economies of scale approach for high (100\%) and low (20\%) vaccination coverage, respectively.

Table 6 displays the ICERs of different coverage levels of the HPV vaccination programme on top of the cervical cancer screening compared to the different coverage of cervical cancer screening alone. The ICERs rely on coverage of cervical cancer screening-the lower the screening coverage was, the better was the value for the HPV vaccination programme given constant unit costs of vaccination and screening programmes (without taking into account economies of scale). These findings are contrary to the results represented in Table 7, in which the economies of scale approach was applied to the costing estimation of both policy options, i.e. vaccine plus cervical cancer screening and cervical cancer screening alone. Most of the scenarios, especially with high vaccination coverage, suggest that the vaccination programme plus cervical cancer screening is a cost-saving option. At low coverage, the vaccination plus cervical cancer screening policy remains a cost-effective option.

Table 8 presents the ICERs for the vaccination programme plus cervical cancer screening using the economies of scale approach compared to the screening programme without taking into account the economies of scale approach. It suggests similar findings to Table 7. 
Table 5 Incremental cost-effectiveness ratio of PCV vaccination compared to no vaccination

\begin{tabular}{|c|c|c|c|c|c|c|}
\hline \multirow[t]{2}{*}{$\%$ coverage } & \multicolumn{3}{|l|}{ PCV10 (USD/QALY) } & \multicolumn{3}{|c|}{ PCV13 (USD/QALY) } \\
\hline & $\begin{array}{l}\text { Without taking } \\
\text { into account EoS } \\
\text { approach }\end{array}$ & $\begin{array}{l}\text { With EoS } \\
\text { approach }\end{array}$ & $\begin{array}{l}\% \text { reduction } \\
\text { of ICER }\end{array}$ & $\begin{array}{l}\text { Without taking } \\
\text { into account EoS } \\
\text { approach }\end{array}$ & $\begin{array}{l}\text { With EoS } \\
\text { approach }\end{array}$ & $\%$ reduction of ICER \\
\hline $10^{\mathrm{a}}$ & 2655 & 1052 & 62 & 1997 & 760 & 71 \\
\hline $20^{\mathrm{a}}$ & 2655 & 975 & 65 & 1997 & 697 & 74 \\
\hline $30^{\mathrm{a}}$ & 2655 & 923 & 67 & 1997 & 650 & 75 \\
\hline $40^{\mathrm{a}}$ & 2655 & 877 & 70 & 1997 & 609 & 77 \\
\hline $50^{\mathrm{a}}$ & 2655 & 834 & 72 & 1997 & 569 & 79 \\
\hline $60^{a}$ & 2655 & 792 & 73 & 1997 & 530 & 80 \\
\hline $70^{\mathrm{a}}$ & 2655 & 750 & 75 & 1997 & 491 & 81 \\
\hline $80^{b}$ & 1439 & 134 & 97 & 1162 & 31 & 98 \\
\hline $90^{b}$ & 1533 & 151 & 97 & 1232 & 38 & 98 \\
\hline $100^{b}$ & 1614 & 159 & 97 & 1292 & 38 & 98 \\
\hline
\end{tabular}

Herd protection was considered at a vaccination coverage rate of $80 \%$

$P C V$ pneumococcal conjugate vaccine, EOS economies of scale, ICER incremental cost-effectiveness ratio

a Low vaccination coverage

b High vaccination coverage

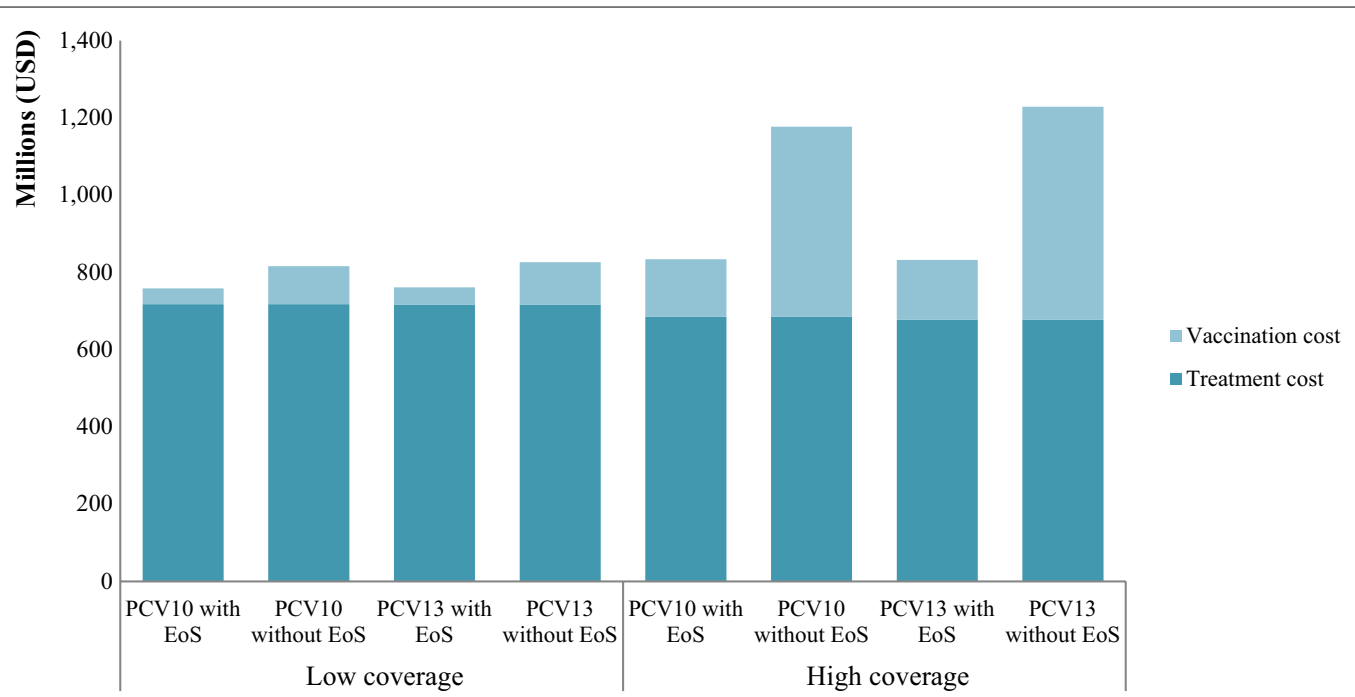

Fig. 1 5-year budget impacts of PCV vaccination programmes with and without applying economies of scale. PCV pneumococcal conjugated vaccine, EoS economies of scale

Table 9 provides different findings-that without taking into account the economies of scale approach for the vaccination programme plus cervical cancer screening but with only the cervical cancer screening programme, the HPV vaccination plus cervical cancer screening policy was cost-ineffective in the Philippines except at $10 \%$ coverage for the screening programme. The higher the screening coverage was, the worse was the value for money of the vaccination programme and this indicated that the screening programme is a better choice for the Philippines.

Figure 2 displays the budget impact of the HPV vaccination programme plus cervical cancer screening with and without taking into account the economies of scale approach. This indicates that in applying the economies of scale approach for economic evaluation, the 5-year budget impacts were 40 and $93 \%$ of the estimation without applying economies of scale at high (100\%) 
Table 6 Incremental cost-effectiveness ratio of HPV vaccination plus cervical cancer screening compared to cervical cancer screening alone: Incremental cost-effectiveness ratio of HPV vaccination and cervical cancer screening without taking into account economies of scale

\begin{tabular}{|c|c|c|c|c|c|c|c|c|c|c|c|}
\hline \multirow{3}{*}{$\begin{array}{l}\text { ICER (USD/QALY) } \\
\text { Percent coverage of HPV vaccine } \\
\text { (not taking into account EoS approach) }\end{array}$} & \multicolumn{11}{|c|}{ Percent coverage of screening (not taking into account EoS approach) } \\
\hline & & 10 & 20 & 30 & 40 & 50 & 60 & 70 & 80 & 90 & 100 \\
\hline & 10 & $-30^{\mathrm{a}}$ & $120^{\mathrm{b}}$ & $270^{b}$ & $440^{b}$ & $600^{b}$ & $770^{b}$ & $940^{b}$ & $1120^{\mathrm{b}}$ & $1300^{\mathrm{b}}$ & $1480^{b}$ \\
\hline & 20 & $-30^{\mathrm{a}}$ & $120^{\mathrm{b}}$ & $270^{b}$ & $440^{b}$ & $600^{b}$ & $770^{b}$ & $940^{b}$ & $1120^{b}$ & $1300^{b}$ & $1480^{b}$ \\
\hline & 30 & $-30^{\mathrm{a}}$ & $120^{b}$ & $270^{b}$ & $440^{b}$ & $600^{b}$ & $770^{b}$ & $940^{b}$ & $1120^{b}$ & $1300^{b}$ & $1480^{b}$ \\
\hline & 40 & $-30^{\mathrm{a}}$ & $120^{\mathrm{b}}$ & $270^{b}$ & $440^{b}$ & $600^{b}$ & $770^{b}$ & $940^{b}$ & $1120^{b}$ & $1300^{b}$ & $1480^{b}$ \\
\hline & 50 & $-30^{\mathrm{a}}$ & $120^{\mathrm{b}}$ & $270^{b}$ & $440^{b}$ & $600^{b}$ & $770^{b}$ & $940^{b}$ & $1120^{b}$ & $1300^{b}$ & $1480^{b}$ \\
\hline & 60 & $-30^{\mathrm{a}}$ & $120^{\mathrm{b}}$ & $270^{b}$ & $440^{b}$ & $600^{b}$ & $770^{b}$ & $940^{b}$ & $1120^{b}$ & $1300^{b}$ & $1480^{b}$ \\
\hline & 70 & $-30^{a}$ & $120^{\mathrm{b}}$ & $270^{b}$ & $440^{b}$ & $600^{b}$ & $770^{b}$ & $940^{b}$ & $1120^{b}$ & $1300^{b}$ & $1480^{b}$ \\
\hline & 80 & $-30^{\mathrm{a}}$ & $120^{b}$ & $270^{b}$ & $440^{b}$ & $600^{b}$ & $770^{b}$ & $940^{b}$ & $1120^{b}$ & $1300^{b}$ & $1480^{b}$ \\
\hline & 90 & $-30^{a}$ & $120^{\mathrm{b}}$ & $270^{b}$ & $440^{b}$ & $600^{b}$ & $770^{b}$ & $940^{b}$ & $1120^{b}$ & $1300^{b}$ & $1480^{b}$ \\
\hline & 100 & $-30^{a}$ & $120^{\mathrm{b}}$ & $270^{b}$ & $440^{b}$ & $600^{b}$ & $770^{b}$ & $940^{b}$ & $1120^{b}$ & $1300^{b}$ & $1480^{b}$ \\
\hline
\end{tabular}

ICER incremental cost-effectiveness ratio, EOS economies of scale, HPV human papillomavirus vaccine

a Cost-effective

b Cost-ineffective

and low (20\%) vaccination plus screening coverage, respectively.

Tables 10, 11, 12, and 13 illustrate the impact of economies of scale in terms of ICERs when comparing the HPV vaccination programme alone with the cervical cancer screening alone. They show a higher impact of the economies of scale approach compared to Tables $6,7,8$, and 9 , resulting in preferable conclusion toward cervical cancer screening, particularly when high coverage of cervical cancer screening is compared to low coverage of HPV vaccination.

\section{Discussion}

The concept of economies of scale indicates that production and delivery unit costs diminish at greater scales of production $[16,17]$. This study demonstrates the importance of using an economies of scale methodological approach in estimating the costs for the economic evaluations and budget impact analyses of the two vaccination programmes. This study assumes that economies of scale for vaccine unit costs yield different ICERs and budget impact estimations compared to conventional costing estimation in economic modelling, which assume constant average programme costs across different levels of service utilization. The new methodological approach may lead to different conclusions from the initial analysis undertaken and in this instance could contribute to alternative policy decisions regarding the adoption and roll-out of the PCV and HPV vaccines in the national vaccination programme in the Philippines. As a result, we believe that using economies of scale in costing estimation for economic evaluations and budget impact analyses is an appropriate approach and better categorises the nature of the problems regarding the decisions that policy makers face in the Philippines.

This is very important, especially in counties that are currently responsible for paying for the vaccine in their vaccination programmes or graduating from GAVI alliance. Further, it demonstrates the substantial impact on vaccine utilisation that GAVI-negotiated pricing could have in countries that do not receive direct GAVI support. Thus, it is in the interest of GAVI and other institutions at national and international levels concerned with improving access to vaccination to increase active support for advancing analytical methods that incorporate economies of scale in economic evaluation and budget impact analysis. These methodological advancements would also better inform National Immunization Technical Advisory Groups (NITAGs) and relevant public health authorities regarding the value for money and budget implications of the vaccine investment. Moreover, this approach is likely to be generalizable to the analysis of other types of technology and interventions beyond the vaccine programme area.

A key finding of this study is that incorporating economies of scale in the cost estimation in economic evaluation yielded higher magnitude of the value for health, especially with high vaccination coverage, in comparison without taking into account economies of scale. Our findings are in line with a systematic review of malaria control intervention conducted by White et al. [18]. The review indicated the effect of the scale of study on estimates of costs based on the number of beneficiaries or patients and concluded that economies of scale 


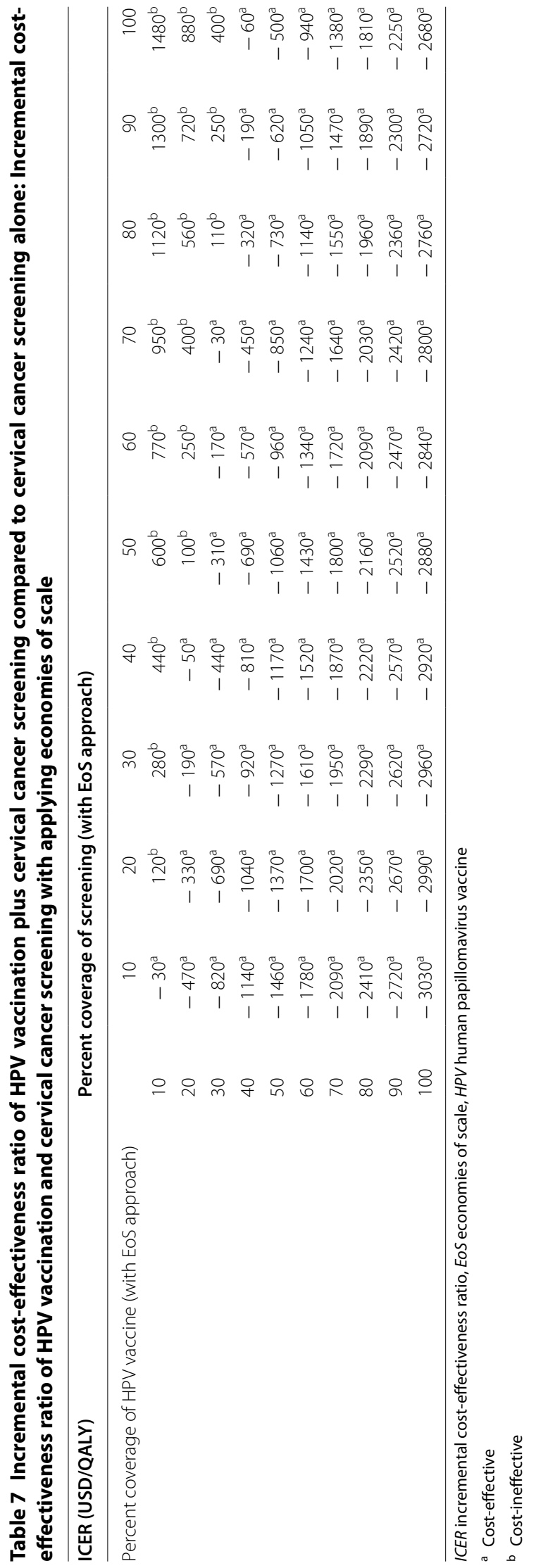




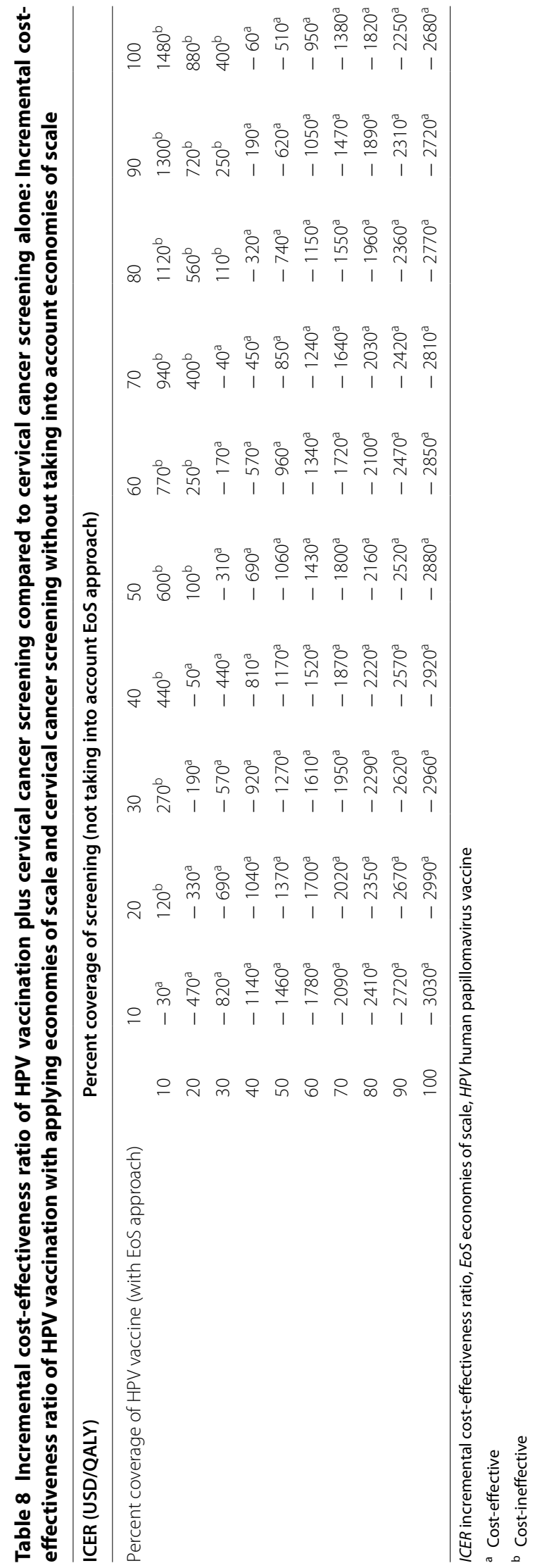


Table 9 Incremental cost-effectiveness ratio of HPV vaccination plus cervical cancer screening compared to cervical cancer screening alone: Incremental cost-effectiveness ratio of HPV vaccination without taking into account economies of scale and cervical cancer screening with applying economies of scale

\begin{tabular}{|c|c|c|c|c|c|c|c|c|c|c|c|}
\hline \multirow{3}{*}{$\begin{array}{l}\text { ICER (USD/QALY) } \\
\text { Percent coverage of HPV vaccine (not taking into } \\
\text { account EOS approach) }\end{array}$} & \multicolumn{11}{|c|}{ Percent coverage of screening (with EoS approach) } \\
\hline & & 10 & 20 & 30 & 40 & 50 & 60 & 70 & 80 & 90 & 100 \\
\hline & 10 & $-30^{a}$ & $120^{\mathrm{b}}$ & $280^{b}$ & $440^{b}$ & $600^{b}$ & $770^{b}$ & $950^{\mathrm{b}}$ & $1120^{\mathrm{b}}$ & $1300^{\mathrm{b}}$ & $1480^{b}$ \\
\hline & 20 & $-30^{\mathrm{a}}$ & $120^{\mathrm{b}}$ & $280^{b}$ & $440^{b}$ & $600^{b}$ & $770^{b}$ & $950^{\mathrm{b}}$ & $1120^{\mathrm{b}}$ & $1300^{\mathrm{b}}$ & $1480^{b}$ \\
\hline & 30 & $-30^{\mathrm{a}}$ & $120^{\mathrm{b}}$ & $280^{b}$ & $440^{\mathrm{b}}$ & $600^{b}$ & $770^{b}$ & $950^{\mathrm{b}}$ & $1120^{b}$ & $1300^{b}$ & $1480^{b}$ \\
\hline & 40 & $-30^{\mathrm{a}}$ & $120^{\mathrm{b}}$ & $280^{b}$ & $440^{b}$ & $600^{b}$ & $770^{b}$ & $950^{\mathrm{b}}$ & $1120^{b}$ & $1300^{b}$ & $1480^{b}$ \\
\hline & 50 & $-30^{\mathrm{a}}$ & $120^{b}$ & $280^{b}$ & $440^{b}$ & $600^{b}$ & $770^{b}$ & $950^{b}$ & $1120^{b}$ & $1300^{b}$ & $1480^{b}$ \\
\hline & 60 & $-30^{\mathrm{a}}$ & $120^{b}$ & $280^{b}$ & $440^{b}$ & $600^{b}$ & $770^{b}$ & $950^{\mathrm{b}}$ & $1120^{b}$ & $1300^{b}$ & $1480^{b}$ \\
\hline & 70 & $-30^{\mathrm{a}}$ & $120^{\mathrm{b}}$ & $280^{b}$ & $440^{b}$ & $600^{b}$ & $770^{b}$ & $950^{\mathrm{b}}$ & $1120^{b}$ & $1300^{b}$ & $1480^{b}$ \\
\hline & 80 & $-30^{\mathrm{a}}$ & $120^{b}$ & $280^{b}$ & $440^{b}$ & $600^{b}$ & $770^{b}$ & $950^{b}$ & $1120^{b}$ & $1300^{b}$ & $1480^{b}$ \\
\hline & 90 & $-30^{\mathrm{a}}$ & $120^{\mathrm{b}}$ & $280^{b}$ & $440^{b}$ & $600^{b}$ & $770^{b}$ & $950^{\mathrm{b}}$ & $1120^{b}$ & $1300^{b}$ & $1480^{b}$ \\
\hline & 100 & $-30^{\mathrm{a}}$ & $120^{\mathrm{b}}$ & $280^{b}$ & $440^{b}$ & $600^{b}$ & $770^{b}$ & $950^{\mathrm{b}}$ & $1120^{b}$ & $1300^{b}$ & $1480^{b}$ \\
\hline
\end{tabular}

ICER incremental cost-effectiveness ratio, EOS economies of scale, HPV human papillomavirus vaccine

a Cost-effective

b Cost-ineffective

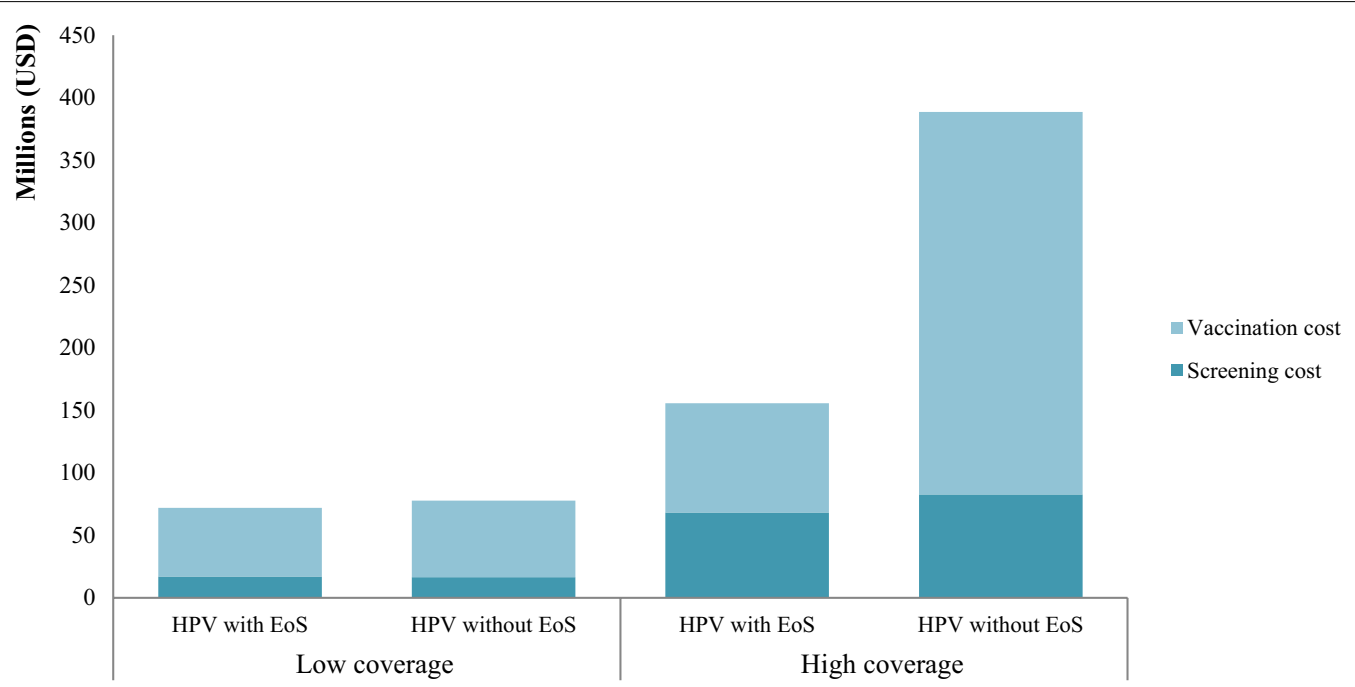

Fig. 2 5-year budget impacts of HPV vaccination programmes with and without applying economies of scale. HPV human papillomavirus vaccine, EoS economies of scale

may result in cost savings per unit when an intervention is widely implemented. Our study adds to the very limited evidence about the relationship and impact of cost and scale of health interventions in terms of determining resource allocation, especially in resource-limited settings. We are aware that our results should be replicated to draw more concrete conclusions. Yet, resent research showed there is a higher tendency to find a positive result due to taking economies of scale than diseconomies and constant economies of scale [19]. However, results still vary across the wide range of settings and the selected outputs. Further studies may apply more accurate data in order to contribute to more productive output for the concept of incorporating economies of scale in cost estimation.

This study has some limitations, mainly related to assumptions required, due to incomplete information on how costs change in relation to volume. In particular, the relationship between the unit cost of vaccine at different levels of vaccine coverage has been approximated using a linear relationship where increasing coverage results in proportionate price reductions. Diseconomies 


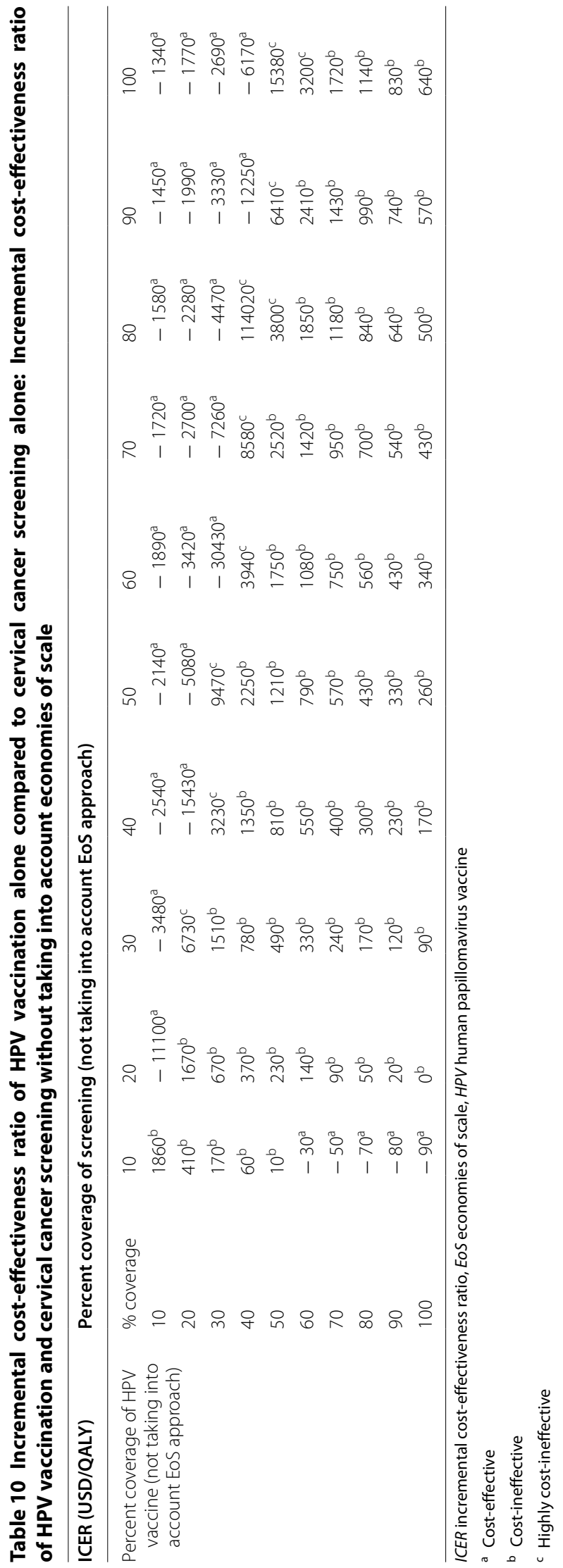




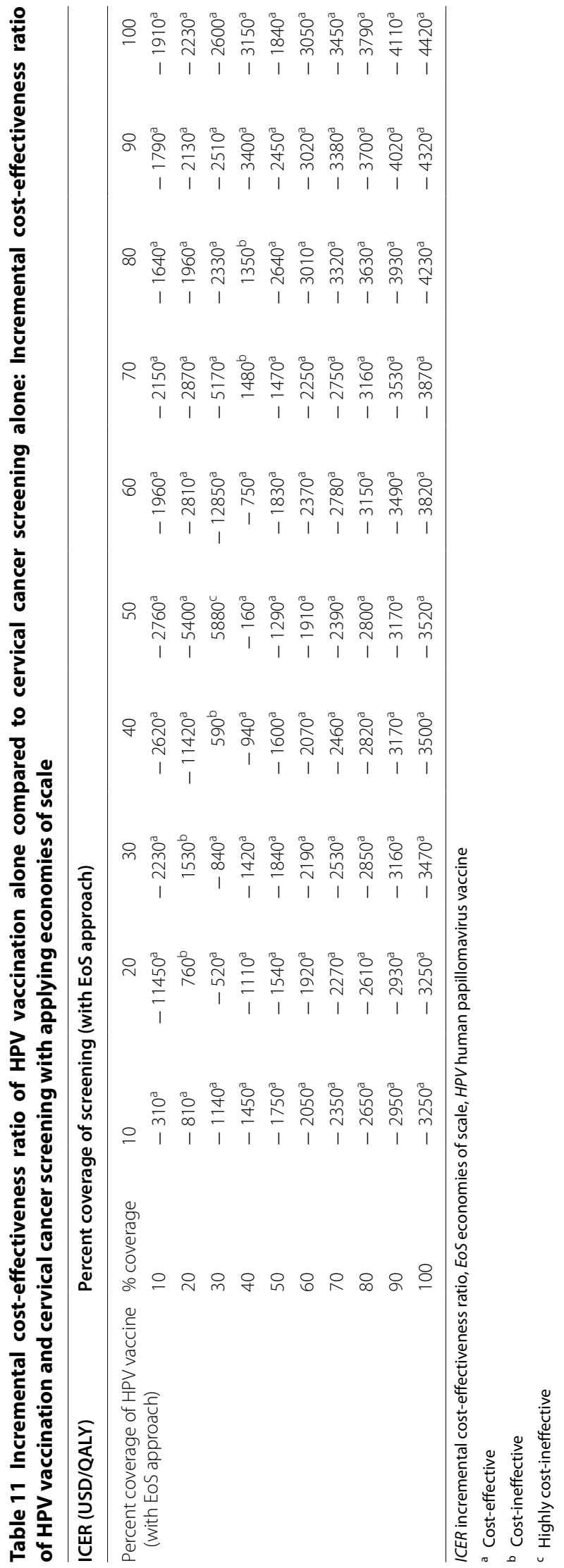




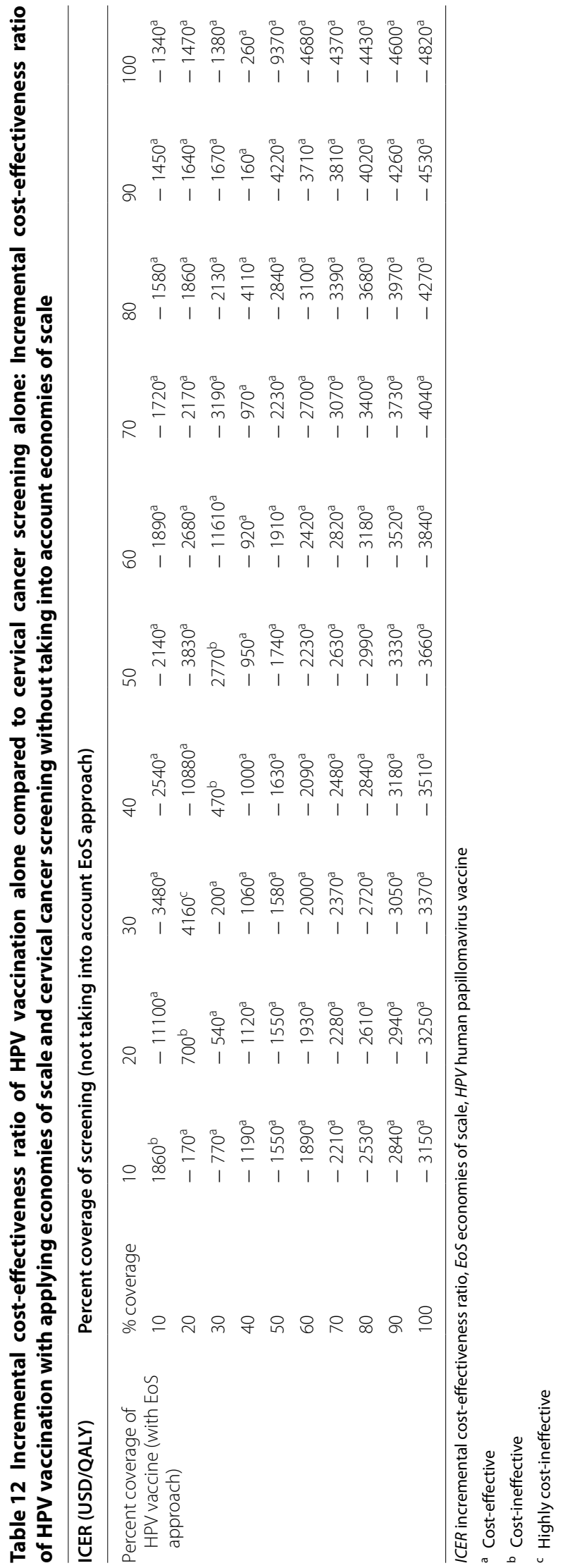




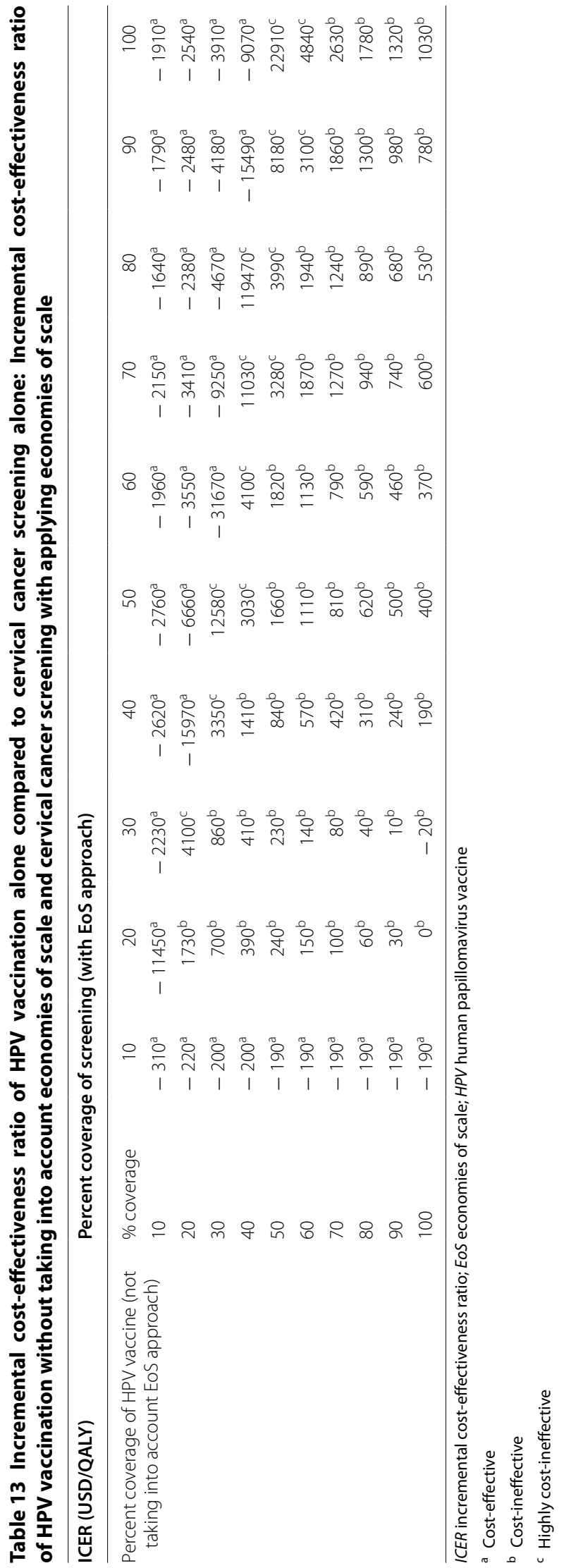


of scale (where the unit cost actually increases with increasing volume) [20] have not been considered in this analysis. Although unit prices for vaccines are unlikely to be affected by diseconomies of scale, geographical and administrative issues may cause some diseconomies, particularly where near universal vaccine coverage is attempted. Second, this study only adopts the government perspective and ignores direct non-medical costs and indirect costs. However, many indirect costs, such as patient travel costs to access health facilities, would be borne on a per patient basis and would be unlikely to change with the number of patients reached by a national programme.

\section{Conclusions}

This analysis has highlighted the need for more research into the production cost function of vaccination programmes and related health services in order to more accurately capture costs at scale, ultimately facilitating better-informed decisions about access to health technologies and interventions.

\section{Abbreviations}

ICERs: incremental cost-effectiveness ratios; CHOICE: WHO's Choosing Interventions that are Cost-Effective project; iDSI: International Decision Support Initiative; PCV: pneumococcal conjugate vaccine; HPV: human papillomavirus vaccine; VIA: visual inspection with acetic acid; QALYs: quality-adjusted life years; USD: US dollars; DPT-HepB-Hib: Diphtheria, Tetanus, Pertussis, Hepatitis $B$ recombinant and Haemophilus influenza type $B$ combined vaccine; $D O H$ : Department of Health; GAVl: Global Alliance for Vaccines and Immunization; $\mathrm{CO}_{2}$ : carbon dioxide; $\mathrm{MOH}$ : Ministry of Health; EoS: economies of scale; NITAGs: National Immunization Technical Advisory Groups.

\section{Authors' contributions}

TS analysed and interpreted the cost, ICERs and budget impact of PCV vaccination regarding the with and without applying economies of scale. NP analysed and interpreted the cost, ICERs and budget impact of HPV vaccination and cervical cancer screening regarding the with and without applying economies of scale. TS was a major contributor in writing the manuscript. All authors read and approved the final manuscript.
\end{abstract}

\section{Author details \\ ${ }^{1}$ Health Intervention and Technology Assessment Program, Ministry of Public Health, Nonthaburi 1 1000, Thailand. ${ }^{2}$ Department of Health Philippines, Pharmaceutical Division, National Center for Pharmaceutical Access and Man- agement, 3/F Building 15, San Lazaro Compound, Rizal Avenue, Sta. Cruz, 1003 Manila, Philippines.}

\section{Acknowledgements}

The authors would like to express the gratitude to NICE International Adviser (Health Economics) Thomas Wilkinson for his technical support and helpful comments during the revision of the manuscript as well as also wish to acknowledge the contribution of Joyce Anne Ceria and Niña Isabelle M. Tolentino from the Pharmaceutical Division, Office for Health Regulations, Department of Health, Manila, Philippines for providing data and reference materials used in the analysis.

\section{Competing interests}

The authors declare that they have no competing interests.

\section{Availability of data and materials}

Not applicable.
Consent for publication

Not applicable.

Ethics approval and consent to participate

Not applicable.

\section{Funding}

The Health Intervention and Technology Assessment Program (HITAP) international unit was established with support from the Thai Health-Global Link Initiative Project (TGLIP) and the International Decision Support Initiative (iDSI) to provide technical assistance on health intervention and technology assessment for governments of low- and middle-income countries. iDSI is funded by the Bill \& Melinda Gates Foundation, the UK's Department for International Development (NICE 849), and the Rockefeller Foundation. Although this study was particularly funded by iDSI; the findings, interpretations and conclusions expressed in this article do not necessarily reflect the views of the funding agencies.

\section{Publisher's Note}

Springer Nature remains neutral with regard to jurisdictional claims in published maps and institutional affiliations.

Received: 13 October 2016 Accepted: 10 January 2018

Published online: 20 February 2018

\section{References}

1. World Health Organization. Health expenditure per capita. World Health Organization Global Health Expenditure Database; 2015.

2. Neumann PJ. Advice for policy makers and politicians. Using cost-effectiveness analysis to improve health care: opportunities and barriers. New York: Oxford University Press; 2005. p. 138-61.

3. Cooper N, Coyle D, Abrams K, Mugford M, Sutton A. Use of evidence in decision models: an appraisal of health technology assessments in the UK since 1997. J Health Serv Res Policy. 2005;10:245-50.

4. Johns B, Torres TT. Costs of scaling up health interventions: a systematic review. Health Policy Plan. 2005;20:1-13.

5. Chisholm D, Evans DB. Economic evaluation in health: saving money or improving care? J Med Econ. 2007;10:325-37.

6. Edejer Tan-Torres T. Making choices in health: WHO guide to cost-effectiveness analysis. Geneva: World Health Organization; 2003.

7. Bill and Melinda Gates Foundation. The gates reference case: what it is, why it's important, and how to use it. Seattle: Bill and Melinda Gates Foundation; 2014. p. 11-2.

8. Gandhi G, Lydon P, Cornejo S, Brenzel L, Wrobel S, Chang H. Projections of costs, financing, and additional resource requirements for low-and lower middle-income country immunization programs over the decade, 2011-2020. Vaccine. 2013;31:B137-48.

9. Department of Health Philippines Vcd: Family Health Office (FHO) Expanded program on immunization (EPI). 2014.

10. Guerrero A, Genuino A, Santillan M, Praditsitthikorn N, Chantarastapornchit $\mathrm{V}$, Teerawattananon $Y$, et al. A cost-utility analysis of cervical cancer screening and human papilloma virus vaccination in the Philippines. BMC Public Health. 2015;15:730.

11. Haasis MA, Ceria JA, Kulpeng W, Teerawattananon Y, Alejandria M. Do pneumococcal conjugate vaccines represent good value for money in a lower-middle income country? A cost-utility analysis in the Philippines. PLOS ONE. 2015;10:e0131156.

12. Department of Health Philippines. Drug price reference index database 2012. Manilla: Department of Health Philippines; 2012.

13. Division US. Human papillomavirus vaccine supply \& demand update. In: UNICEF HPV vaccine LTA awards for Gavi-eligible countries 2013-2017. København: UNICEF Supply Division; 2015. p. 5.

14. Gavi The Vaccine Alliance. Gavi supply and procurement roadmap Streptococcus pneumoniae. Geneva: Gavi The Vaccine Alliance; 2016. p. 2.

15. Path WHO. An assessment of vaccine supply chain and logistics systems in Thailand. Mahidol: Mahidol University: Health Systems Research Institute; 2011. 
16. Peltokorpi A, Torkki P, Jousela I, Lepäntalo M. Economy of scale and scope in healthcare operations: lessons from surgical services. In: POMS 23rd annual conference; Chicago, Illinois, USA; 2011.

17. Gaynor M, Seider H, Vogt WB. The volume-outcome effect, scale economies, and learning-by-doing. Am Econ Rev. 2005;95:243-7.

18. White MT, Conteh L, Cibulskis R, Ghani AC. Costs and cost-effectiveness of malaria control interventions-a systematic review. Malar J. 2011;10:1475-2875.
19. Hernandez-Villafuerte K, Sussex J, Robin E, Guthrie S, Wooding S. Economies of scale and scope in publicly funded biomedical and health research: evidence from the literature. Health Res Policy Syst. 2017;15:3.

20. Besanko D, Dranove D, Shanley M, Schaefer S. Economies of scale and scope. In: Economics of strategy. 5th edition international student version edition. New York: Wiley; 2009. p. 41-72.

\section{Submit your next manuscript to BioMed Central and we will help you at every step:}

- We accept pre-submission inquiries

- Our selector tool helps you to find the most relevant journal

- We provide round the clock customer support

- Convenient online submission

- Thorough peer review

- Inclusion in PubMed and all major indexing services

- Maximum visibility for your research

Submit your manuscript at www.biomedcentral com/submit 